\title{
Effects of simulated shoot and leaf herbivory on vegetative growth and plant defense in Acacia drepanolobium
}

\author{
Michelle E. Gadd, Truman P. Young and Todd M. Palmer
}

Gadd, M. E., Young, T. P. and Palmer, T. M. 2001. Effects of simulated shoot and
leaf herbivory on vegetative growth and plant defense in Acacia drepanolobium. Oikos 92: 515-521.

Plants have considerable ability to respond to herbivory, both with (above-ground) regrowth and with increased defense. We simulated both leaf and shoot herbivory in controlled, replicated experiments on individuals of Acacia drepanolobium in Laikipia, Kenya. These experiments were carried out on individuals that had experienced different, experimentally controlled histories of large mammalian herbivory. Both forms of simulated herbivory were associated with compensatory regrowth. Branches whose shoots had been removed grew significantly more over the next year than paired control branches, fully compensating for the lost shoot length. Branches whose leaves were removed both grew faster and had more leaves one year later than did control branches. Shoot removal, but not leaf removal, increased the production of side shoots. However, because past herbivore pressure was negatively associated with net shoot growth, there may be a long-term cost of herbivory even when plants appear to fully compensate for herbivory in the short term. In contrast to the effects on growth, simulated herbivory did not significantly increase physical (spines) or chemical (tannins) defenses, and there were no significant negative correlations between compensatory growth and plant defense.

M. E. Gadd and T. M. Palmer, Ecology Graduate Group, Univ. of California, Davis, CA 95616, USA. - T. P. Young (correspondence), Dept of Environmental Horticulture, Univ. of California, Davis, CA 95616, USA (tpyoung@ucdavis.edu).

A plant may respond to herbivore attack via tolerance, compensation, and/or induced defense. Tolerance is a plant's ability to withstand and survive damage. Compensation is increased plant growth after loss of tissue to herbivores (Strauss and Agrawal 1999). Induced responses to herbivory are called induced defense when they are known to decrease rates of herbivory (Karban and Baldwin 1997).

Compensation for herbivory is frequently reported in grasses (McNaughton 1983, Milchunas and Lauenroth 1993, Milchunas et al. 1995, Bush and Vanauken 1995, Varnamkhasti et al. 1995). Compensatory growth has also been found in herbs (Whitham et al. 1991, Paige 1992, Alados et al. 1997, Cebrian et al. 1998, Meyer 1998, Lennartsson et al. 1998, Paige 1999), shrubs (Oba 1994, Tolvanen and Laine 1997, Oba et al. 2000), and trees (Honkanen et al. 1994, Dangerfield and Mod- ukanele 1996, Kudo 1996, Bergström et al. 2000) (see also review in Strauss and Agrawal 1999). Responses to herbivory may depend on the timing of herbivory, the type and extent of herbivory, the availability of resources in the environment to support regrowth (McNaughton 1983, Rosenthal and Kotanen 1994), and the grazing/browsing history of the plant (McNaughton 1983, Paige 1992, Lennartsson et al. 1997).

Plants can also respond to herbivory by increasing their defensive capabilities. This induced defense can be adaptive in situations where herbivory is variable, and where current herbivory is a good predictor of future herbivory (Karban and Baldwin 1997, Agrawal 1998). Spine length in African Acacia spp. is an example of an inducible physical defense. Spines are effective defenses, deterring mammalian browsers in many Acacia species by impeding bite rate and size, and total herbivory

Accepted 30 October 2000

Copyright C OIKOS 2001

ISSN 0030-1299

Printed in Ireland - all rights reserved 
(Cooper and Owen-Smith 1986, Milewski et al. 1991). Acacia trees growing in areas with low mammal densities produced shorter spines than elsewhere (Milewski et al. 1991, Young and Okello 1998). Within trees, branches out of reach of herbivores produced shorter spines than lower branches (Young 1987, Milewski et al. 1991). Although we now have controlled, replicated experiments that show relaxation in spine length after exclusion of herbivores (Young and Okello 1998), we have not yet shown experimentally the ability of trees to re-induce greater spine lengths in the same setting.

One might predict a trade-off between investing in compensatory growth or investing in induced defenses (van der Meijden et al. 1988, Fineblum and Rausher 1995, Sagers and Coley 1995). Compensation from herbivory has been associated with other fitness costs, including reduced survivorship (Ruohomäki et al. 1997, Meyer 1998), growth (Meyer 1998), or reproduction (Ruohomäki et al. 1997). However, compensation and defenses are not necessarily mutually exclusive, and investment in one need not limit investment in the other (Mauricio et al. 1997, Augustine and McNaughton 1998, Strauss and Agrawal 1999). Recent studies indicate that some woody species have both enhanced above-ground growth and increased tannin levels after browsing (du Toit et al. 1990, Stock et al. 1993).

We carried out a study on the tropical tree Acacia drepanolobium. Our experiments are different from previous studies of simulated herbivory in that we simulated two kinds herbivory (on leaves and on shoots) on separate branches of the same trees (cf. Honkanen et al. 1994, Oba 1994, Alados et al. 1997) and monitored both compensatory growth and induced defence. This uniquely allowed us to compare all of these treatments and responses in a system that controls for plant species, and time and site effects. In addition, this experiment was embedded inside a large-scale herbivore exclusion experiment (Young et al. 1998), allowing us to analyze short-term responses to simulated herbivory in the context on longer-term differences in actual herbivory.

\section{Methods}

\section{Study site and species}

The study was conducted at the Kenya Long-term Exclosure Experiment (KLEE; Young et al. 1998) at the Mpala Research Centre in Laikipia District, Kenya. The study area is located at an elevation of $1800 \mathrm{~m}$ a.s.1. $\left(0^{\circ} 17^{\prime} \mathrm{N}, 37^{\circ} 52^{\prime} \mathrm{E}\right)$. The climate is semi-arid, averaging $\sim 500 \mathrm{~mm}$ of rain in a complex seasonal pattern. The vegetation in the study plots is Acacia drepanolobium bushed grassland, characteristic of heavy clay "black cotton" soils of impeded drainage. A series of 18 four-ha plots were constructed in September 1995 to selectively exclude 1) all large herbivores, 2) all large herbivores except cattle, 3) elephants and giraffes, 4) elephants, giraffes, and cattle, 5) cattle only. The sixth plot in each replicate is accessible to all animals. In each of three blocks, all six treatments were arranged in a random stratified design. Large herbivores were excluded by a nine-strand electric fence $2.2 \mathrm{~m}$ high. Elephants and giraffes were excluded by a fence with two strands at a height of 2-2.2 m. Cattle are individually herded, and visual barriers were used to direct herdsmen away from cattle exclusion plots. Both dung count data and browsing data on Acacia drepanolobium demonstrate that these barriers are effective in excluding the target herbivores (Young and Okello 1998, Young et al. 1998). See Young et al. (1998) for a full description of KLEE.

The simulated herbivory experiment was conducted on Acacia drepanolobium. This tree is small and singlestemmed, occurring in East Africa on soils of impeded drainage. It is defended by spines (Young 1987, Milewski et al. 1991), symbiotic ants (Madden and Young 1992, Young et al. 1997), and perhaps leaf chemistry (Ward and Young unpubl.). Each tree is inhabited by one of four species of ants living in swollen spines (Young et al. 1997 and Palmer et al. 2000). Treatments were stratified across trees with the four common ant species: Crematogaster mimosae, $C$. nigriceps, C. sjostedti, and Tetraponera penzigi. The presence of particular ant species has myriad effects on tree growth, reproduction, and morphology (see Young et al. 1997 and Stanton et al. 1999). Local mammalian herbivores of $A$. drepanolobium include elephants, giraffes, elands, Grant's gazelles, and steinbucks.

\section{Simulated herbivory}

In July 1997, in each of the 18 experimental plots, we selected four trees, one occupied by each of the four resident ant species. Working along one side of each plot, we selected trees within $25 \mathrm{~m}$ of the plot edge, choosing the first tree that a) was occupied by an ant species not previously sampled, b) had accessible branches $1.0-1.5 \mathrm{~m}$ from the ground, and c) had one or two forked branches that could be used for paired treatments. We also sampled one tree in each plot (18 more trees) with the dominant ant Crematogaster mimosae that had branches $\sim 2.0 \mathrm{~m}$ from the ground (rarely, this was the same tree as sampled for lower branches). In total, we had 90 experimental branch pairs for each of the two forms of simulated herbivory.

On each tree, one forked branch pair was designated for leaf removal, and the other for shoot removal. Evidence suggests that individual branches within a tree are relatively autonomous (Sprugel et al. 1991). Occasionally (five cases) these two forms of simulated herbivory were on different trees. On each forked branch, 
one fork was designated "experimental" and the other "control". This designation alternated from tree to tree, with the proximity to the side of the plot being the reference direction. The distance from the fork point to the end of the shoot was measured for each of the forks, as was the average height each of the two forked branches. On each of the selected shoots, we measured five $\mathrm{cm}$ from the shoot tip, and then sampled the next two nodes more proximate to the stem. If either was a swollen spine, it was skipped and the next node was chosen. At each node, one of the pair of spines was measured to the nearest $\mathrm{mm}$. If the two spines were visibly different in size, the one most vertical was measured. The height of the tree and the identity of its ant occupant were also recorded.

The terminal $3 \mathrm{~cm}( \pm 1 \mathrm{~cm})$ of the shoot removal branch was pulled off with a pair of pliers. All leaves were plucked from the leaf removal fork. In July and August of 1998, these trees were resurveyed. Eight trees (out of 90) could not be relocated. Each of the four branches was measured to its furthest living shoot, and the number of shoots per branch was counted. For the shoot removal branch, we also measured the distance to the stub where the shoot had been removed. We again measured two spines per branch on new growth as described above. If there was no new growth, no spines were measured. If the new growth was not long enough for this method (five $\mathrm{cm}$ plus two internodes), we measured the spines on the first two nodes of the new growth.

On the leaf removal treatment and control branches, we also counted the numbers of axillary leaves per node. We surveyed the first four nodes of new growth (since the last growth period April to June 1998) and the last four nodes of old growth. Many of the leaves on the older parts of the shoots were produced during the year between surveys, and so these sections of shoots could have more or fewer leaves in the second survey than in the first.

\section{Statistical analysis}

All tests of simulated herbivory treatment effects were based on paired comparisons. For each branch pair, we calculated the difference between control and treatment branches for the response variables: number of shoots, branch length, and mean spine length. For the simulated leaf herbivory experiments, we also analyzed the numbers of old and new leaves. These differences were our primary response variables. The means of these responses were compared with an expectation of no difference, with the exception of shoot length on shoot removal branch pairs, which were compared with an expectation of a loss of $3 \mathrm{~cm}$ (the amount of shoot tip removed). These analyses were done on all relocated plants.
Variation in these responses were then compared across blocks, ant species, herbivore treatments with interactions in split-split plot, three-way ANOVAs (Type III Sum of Squares) corrected for missing replicates (lost trees and dead shoots). For these analyses, we did not include the 18 trees with higher sampled branches because these were only occupied by $C$. $m i$ mosae. Herbivore treatment levels were reduced to three by not distinguishing between plots accessible to cattle and not accessible (cattle do not feed on A. drepanolobium). We also ran correlation analyses between the individual responses (differences between experimental and control branches) and mean shoot growth rates on each tree.

\section{Results}

\section{Leaf removal experiment}

Mortality rates in leaf removal (7/86) and leaf control $(6 / 86)$ branches were similar. Among surviving branches, the production of side shoots was independent of leaf removal treatment $(t=0.62, \mathrm{df} .=69, p=$ 0.54 ; Fig. 1). However, leaf removal branches grew faster than their paired control branches by an average of $3.25 \mathrm{~cm}(t=2.02$, df. $=69, p=0.04$; Fig. 2). The strength of the growth response to herbivory was independent of block $(F=0.01$, df. $=2, p=0.99)$, ant species $(F=0.52, \quad$ df. $=3, \quad p=0.48), \quad$ and herbivore exclosure treatment $(F=1.25$, df. $=2, p=0.39)$.

Leaf removal branches had $24 \%$ more leaves per node than leaf control branches $(t=2.40, \mathrm{df} .=69$, $p=0.02$; Fig. 3). When new and old leaves were analyzed separately, the effect was greater for new leaves

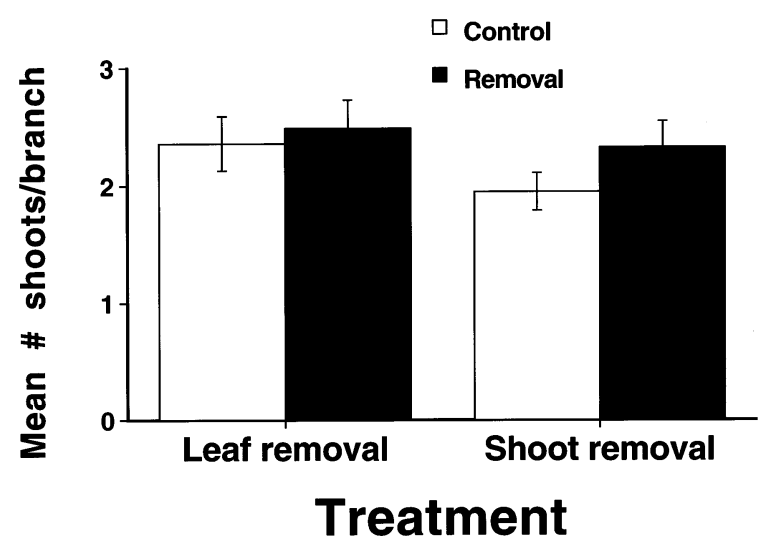

Fig. 1. Effects of leaf removal and shoot removal on the eventual number of shoots per branch. Sample sizes were 86 or 87 for each sample. Bars are one standard error, calculated across trees. Statistics were done on comparisons that controlled for individual tree effects, which greatly increase power compared to the apparently large standard errors shown here. Shoot removal significantly increased the number of shoots per branch, but leaf removal did not. 


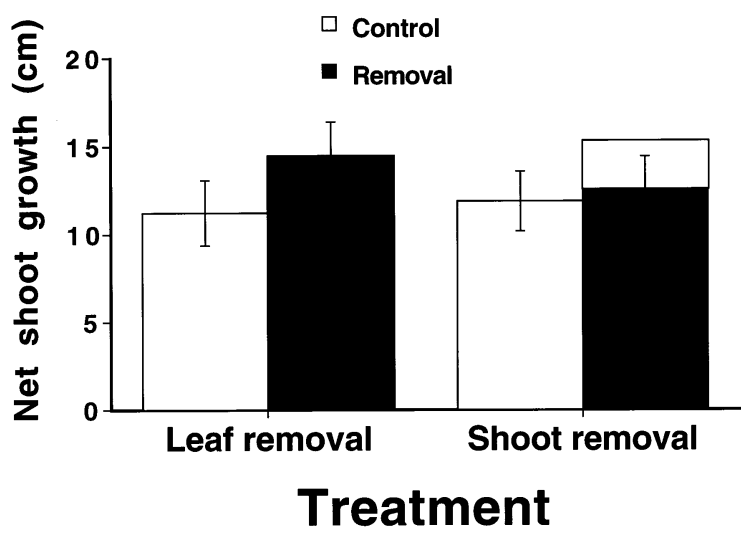

Fig. 2. Effects of leaf removal and shoot removal on subsequent shoot growth. Sample sizes were 86 or 87 for each sample. Bars are one standard error, calculated across trees. Statistics were done on comparisons that controlled for individual tree effects, which greatly increase power compared to the apparently large standard errors shown here. The white area represents the mean length of shoot tip removed; i.e., the shoot removal branches had grown faster than the control branches by an amount that fully compensated for the loss of their tips.

$(t=2.36$, df. $=69, p=0.02)$. Both old and new leaf regrowth responses to leaf removal were independent of block (old: $F=0.07$, df. $=2, p=0.93$; new: $F=0.02$, df. $=2, p=0.98)$, and herbivore exclusion treatment (old: $F=15$, df. $=2, p=0.87$; new: $F=0.57$, df. $=2$, $p=0.61)$. The response of old leaves was also independent of ant species $(F=0.82$, df. $=3, p=0.49)$. However, trees occupied by $C$. nigriceps and $C$. mimosae responded significantly more to simulated leaf herbivory by producing new leaves than did trees occupied by $C$. sjostedti and $T$. penzigi $(F=2.75$, df. $=3, p=$ 0.05; Fig. 3).

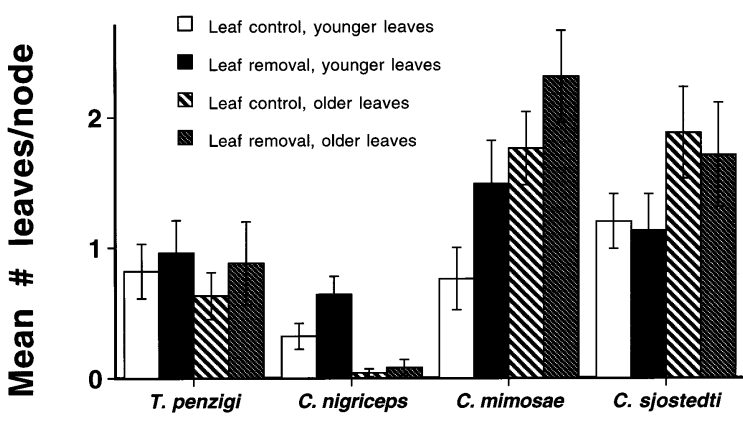

Ant Species

Fig. 3. Effects of leaf removal on the mean number of leaves per node on trees occupied by different ant species. Sample sizes were 17 or 18 for each sample. Bars are one standard error, calculated across trees. Statistics were done on comparisons that controlled for individual tree effects, which greatly increase power compared to the apparently large standard errors shown here. Leaf removal significantly increased leaf production, overall.
Spine lengths did not respond to leaf removal. Leaf removal and leaf control spines were similar in length both years and did not undergo dramatic growth between years (mean difference $-0.08 ; t=0$., df. $=34$, $p=0.55)$.

\section{Shoot removal experiment}

Shoot removal branches were 4.5 times as likely to die over the next year than were shoot control branches (9/87 vs $\left.2 / 87, \chi^{2}=3.49, p=0.04\right)$. Among surviving branches, leaf removal branches had significantly more shoots $(2.32 \pm 0.22)$ than shoot control branches $(1.95 \pm 0.16 ; t=2.05$, df. $=63, p=0.04$; Fig. 1$)$. Among surviving branches, those that had $3 \mathrm{~cm}$ of shoot tip removed in 1997 grew more than their unclipped counterparts $(t=1.99$, df. $=63, p=0.05$; Fig. 2$)$, and within one year had regained the treatment loss by growing an average of $3.25 \mathrm{~cm}$ more than the paired controls. The increase in branch growth rate associated with simulated shoot herbivory was independent of block $(F=$ 3.05 , df. $=2, p=0.08)$, ant species $(F=0.58$, df. $=3$, $p=0.64)$, and herbivore treatment $(F=3.70$, df. $=2$, $p=0.12)$. The increase in the number of shoots produced per branch with simulated shoot herbivory was also independent of ant species $(F=1.25$, df. $=3, p=$ $0.33)$, and herbivore treatment $(F=1.95$, df. $=2, p=$ $0.26)$, although there was a block effect $(F=3.83$, df. $=2, p=0.05)$.

Average shoot growth was strongly influenced by ant occupant $(F=4.36$, df. $=63, p=0.01)$. Trees occupied by Tetraponera penzigi experienced the highest growth $($ mean $=20.8 \mathrm{~cm})$, followed by Crematogaster mimosae $(12.4 \mathrm{~cm}), C$. nigriceps $(10.0 \mathrm{~cm})$, and C. sjostedti $(6.9$ $\mathrm{cm})$. Herbivores also had a significant influence on branch regrowth. Branches grew $60 \%$ faster in plots from which all browsers had been excluded (14.1 \pm 3.0 $\mathrm{cm})$ than in the plots accessible to browsers $(8.7 \pm 1.7$ $\mathrm{cm} ; F=3.05$, df. $=63, p=0.025$ ). This paralleled a similar, but not significant difference in the leaf treatment branches. These differences were not due to direct herbivory, which did not occur on any of the study branches during this year.

All forms of vegetative compensation were positively correlated with mean shoot growth, and one such comparison was statistically significant. The response of leaf number to leaf removal was significantly greater on branch pairs with greater mean growth rates $(F=6.04$, df. $=63, p=0.02$ ).

\section{Discussion}

Acacia drepanolobium demonstrates considerable ability to compensate for the loss of vegetative tissue. Both shoot removal and leaf removal were effective stimuli 
for regrowth. Shoot regrowth was fully compensatory in shoot removal experiments. Leaf regrowth was so much greater in leaf removal branches that these had significantly more leaves a year later than did branches from which no leaves had been removed. Shoot removal, but not leaf removal, increased the production of side shoots. This suggests that the production of side shoots was the result of the loss of apical dominance.

Acacia species, including $A$. drepanolobium, suffer considerable herbivory in nature. They are preferred food for giraffes, which both strip branches of their leaves and nip young shoots (Pellew 1983, Milewski et al. 1991, Young and Isbell 1991). In a given year, $5-15 \%$ of shoot tips in this study site are eaten by herbivores (Young and Okello 1998, Young et al. 1998). Given that these trees are predictably browsed by herbivores, it is perhaps not surprising that this tree has the ability to compensate for some forms of herbivory. We can add $A$. drepanolobium to the growing list of species that show regrowth responses to herbivory. Our observed responses to simulated herbivory were elicited without any chemical cues or stimulants (e.g., saliva) from herbivores.

Previous surveys had shown that our herbivore exclusion barriers effectively reduce shoot herbivory (Young and Okello 1998, Young et al. 1998). We now have evidence that exclusion was associated with $60 \%$ greater shoot growth on trees protected from browsers (see Results). This result implies that there may be at least some costs of herbivory that are not fully recoverable by shoot regrowth, either differences in shoot mortality or systemic responses of trees to herbivory.

Vegetative compensation was positively correlated with growth rate. There were parallel differences in compensation among trees occupied by different ant species, which were correlated with their different mean growth rates (see below). It is likely that when limiting resources are more available, plants are more able to compensate for tissue loss.

In interspecific comparisons, faster growing plants are more likely to recover, perhaps because they can regain biomass more quickly (Coley et al. 1985). Within populations, the ability of a plant to compensate for tissue loss also appears to be positively related to factors that determine its ability to acquire energy, such as growing season (Oba 1994, Bush and Vanauken 1995, Alados et al. 1997), branch size (Honkanen and Haukioja 1994), fertilization and lack of competition (Mutikainen and Walls 1995), and light availability (Lentz and Cipollini 1998). In addition, the ability to compensate may be greater in the absence of other resource sinks, such as reproductive structures (Tolvanen and Laine 1997), or adjacent defoliated branches (Honkanen et al. 1994). The ability to store and mobilize carbohydrates was thought to determine resilience, but recent evidence has failed to support this (Stock et al. 1993).
In contrast, there were no indications that our simulated herbivory induced either physical defenses (spine length) or chemical defenses (tannin concentrations; Ward and Young unpubl.). We call these traits defenses. There is strong experimental evidence that spines do indeed defend plants from herbivory (Cooper and Owen-Smith 1986, Milewski et al. 1991, Gowda 1996). The defensive role of tannins is the subject of recent reconsideration, but there is qualified support for this role (Wrangham and Waterman 1981, Cooper and Owen-Smith 1985, Furstenburg and van Hoven 1994).

There are at least two possible reasons why our experiments failed to demonstrate induction of these defenses. First, our simulated herbivory may have differed from natural herbivory in ways that failed to provide the appropriate cues to the plants (Agrawal 1998). Second, these defenses may already have been largely induced by past herbivory. After two and a half years of herbivore exclusion, both spine length (Young and Okello 1998) and tannin concentrations (Ward and Young unpubl.) had been reduced only $\sim 20 \%$, barely detectable given the large variation in these traits, even with large sample sizes (720 and 180 trees, respectively). Even if our treatments had fully reversed these small decreases, we may not have had the power to detect it (with 72-90 trees). This may also explain why neither vegetative nor defensive responses differed among the different herbivore treatment classes.

There were no negative correlations between compensation (difference between treatments and controls) and either chemical (tannins) or physical (spines) defenses, and only positive correlations with mean growth rates. Acacia drepanolobium is a long-lived plant, and costs of vegetative compensation might be expressed in terms of reduced future growth, reproduction, or survival, but this is by no means certain (see Whitham et al. 1991, Vail 1992, Paige 1999).

Many traits of $A$. drepanolobium trees are significantly correlated with the species of ant occupant (Young et al. 1997, Young and Okello 1998). We have shown here that trees occupied by different ant species differed in their mean shoot growth, and in two of the three compensatory responses to simulated herbivory. These may be causally related or separate syndromes related to particular ant behaviors as yet undescribed.

Trees occupied by different ants differed both in the mean number of leaves per node, and the response of this variable to artificial defoliation (Fig. 3). The very low number of leaves per node associated with $C$. nigriceps results from their unique behavior of removing many of the axillary shoots that produce new leaves (Young et al. 1997, Stanton et al. 1999). Even with few nodes available, however, trees occupied by $C$. nigriceps strongly compensated for leaf loss. In contrast, trees occupied by $C$. sjostedti did not quite fully compensate for leaf loss. This is consistent with the facts that a) trees occupied by $C$. sjostedti had the lowest mean 
shoot growth, and b) shoot growth was positively correlated with compensatory leaf production.

In summary, Acacia drepanolobium exhibits considerable ability to regrow after simulated herbivory. The difference between the regrowth of treatment and control branches was positively correlated with plant growth rates, which were themselves correlated with both the identity of the ant symbiont, and the experimentally controlled past history of herbivory. While these plants demonstrated an ability to regrow after our simulated herbivory, the overall growth rates of plants exposed to experimentally controlled herbivory $(60 \%$ greater in plants protected from herbivores) suggest that there are long-term costs to herbivory that may not be evident in short-term studies.

Acknowledgements - We thank Mpala Research Centre, the Office of the President of the Republic of Kenya (OP/13/001/ 8C 20/48), The Smithsonian Institution, The National Geographic Society (grant 4691-91), the National Science Foundation (BSR 93-07477), and the University of California Research Expeditions Program for their support. Special thanks to George Small, John Wreford, John Ruggieri, and Janice Gleason. Assistance in the field was provided by Frederick Erei, John Lemboi and the 1997 and 1998 Kenya UREP volunteers. Neil Willits was of tremendous help with the statistical analyses. We received useful comments on the ms from Norman Owen-Smith, Lissy Coley, Rick Karban, Anurag Agrawal and Jennifer Thaler.

\section{References}

Agrawal, A. A. 1998. Induced responses to herbivory and increased plant performance. - Science 279: 1201-1202.

Alados, C. L., Barroso, G. and Garcia, L. 1997. Effects of early season defoliation on above-ground growth of $\mathrm{An}$ thyulis cytisoides, a Mediterranean browse species. - J. Arid Environ. 37: 269-283.

Augustine, D. J. and McNaughton, S. J. 1998. Ungulate effects on the functional species composition of plant communities: herbivore selectivity and plant tolerance. - J. Wildl. Manage. 62: 1165-1183.

Bergström, R., Skarpe, C. and Danell, K. 2000. Plant responses and herbivory following simulated browsing and stem cutting of Combretum apiculatum. - J. Veg. Sci. 11: 409-414.

Bush, J. K. and Vanauken, O. W. 1995. Woody plant growth related to planting time and clipping of a C-4 grass. Ecology 76: 1603-1609.

Cebrian, J., Duarte, C. M., Agawin, N. S. R. and Merino, M. 1998. Leaf growth response to simulated herbivory: a comparison among seagrass species. - J. Exp. Mar. Biol. Ecol. 220: 67-81.

Coley, P. D., Bryant, J. P. and Chapin, F. S. 1985. Resource availability and plant antiherbivore defense. - Science 230 : 895-899.

Cooper, S. M. and Owen-Smith, N. 1985. Condensed tannins deter feeding by browsing ungulates in a South African savanna. - Oecologia 67: 142-146.

Cooper, S. and Owen-Smith, N. 1986. Effects of plant spinescence on large mammalian herbivores. - Oecologia 68 $446-455$.

Dangerfield, J. M. and Modukanele, B. 1996. Overcompensation by Acacia erubescens in response to simulated browsing. - J. Trop. Ecol. 12: 905-908.

du Toit, J. T., Bryant, J. P. and Frisby, K. 1990. Regrowth and palatability of Acacia shoots following pruning by African savanna browsers. - Ecology 71: 149-154.
Fineblum, W. L. and Rausher, M. D. 1995. Tradeoff between resistance and tolerance to herbivore damage in a morning glory. - Nature 377: 517-520.

Furstenburg, D. and van Hoven, W. 1994. Condensed tannin as anti-defoliate agent against browsing by giraffe (Giraffa camelopardalis) in the Kruger National Park. - Comp. Biochem. Physiol. 107: 425-431.

Gowda, J. H. 1996. Spines of Acacia tortilis: what do they defend and how? - Oikos 77: 279-284.

Honkanen, T. and Haukioja, E. 1994. Why does a branch suffer more after branch-wide than after tree-wide defoliation. - Oikos 71: 441-450.

Honkanen, T., Haukioja, E. and Suomela, J. 1994. Effects of simulated defoliation and debudding on needle and shoot growth in Scots pine Pinus sylvestris - implications of plant source-sink relationships for plant-herbivore studies. - Funct. Ecol. 8: 631-639.

Karban, R. and Baldwin, I. T. 1997. Induced responses to herbivory. - Univ. of Chicago Press.

Kudo, G. 1996. Herbivory pattern and induced responses to simulated herbivory in Quercus mongolica var grosseserrata. - Ecol. Res. 11: 283-289.

Lennartsson, T., Nilsson, P. and Tuomi, J. 1998. Induction of overcompensation in the field gentian, Gentianella campestris. - Ecology 79: 1061-1072.

Lennartsson, T., Tuomi, J. and Nilsson, P. 1997. Evidence for an evolutionary history of overcompensation in the grassland biennial Gentianella campestris (Gentianaceae). - Am. Nat. 149: $1147-1155$

Lentz, K. A. and Cipollini, D. F. 1998. Effect of light and simulated herbivory on growth of endangered northeastern bulrush, Scirpus ancistrochaetus Schuyler. - Plant Ecol. 139: $125-131$.

Madden, D. and Young, T. P. 1992. Ants as alternative defenses in spinescent Acacia drepanolobium. - Oecologia 91: $235-238$.

Mauricio, R., Rausher, M. D. and Burdick, D. S. 1997. Variation in the defense strategies of plants: are resistance and tolerance mutually exclusive? - Ecology 78: 13011311.

McNaughton, S. J. 1983. Compensatory plant growth as a response to herbivory. - Oikos 40: 329-336.

Meyer, G. A. 1998. Pattern of defoliation on its effect on photosynthesis and growth of Goldenrod. - Funct. Ecol. 12: $270-279$.

Milchunas, D. G. and Lauenroth, W. K. 1993. Quantitative effects of grazing on vegetation and soils over a global range of environments. - Ecol. Monogr. 63: 327-366.

Milchunas, D. G., Varnamkhasti, A. S., Lauenroth, W. K. and Goetz, H. 1995. Forage quality in relation to longterm grazing history, current-year defoliation, and waterresource. - Oecologia 101: 366-374.

Milewski, A. V., Young, T. P. and Madden, D. 1991. Thorns as induced defenses: experimental evidence. - Oecologia 86: $70-75$.

Mutikainen, P. and Walls, M. 1995. Growth, reproduction and defense in nettles-responses to herbivory modified by competition and fertilization. - Oecologia 104: 487-495.

Oba, G. 1994. Responses of Indigofera spinosa to simulated herbivory in a semidesert of north-west Kenya. - Acta Oecol. 15: 105-117.

Oba, G., Mengistu, Z. and Stenseth, N. C. 2000. Compensatory growth of the African dwarf shrub Indigofera spinosa following simulated herbivory. - Ecol. Appl. 10: 11331146.

Paige, K. N. 1992. Overcompensation in response to mammalian herbivory: from mutualistic to antagonistic interactions. - Ecology 73: 2076-2085.

Paige, K. N. 1999. Regrowth following ungulate herbivory in Ipomopsis aggregata: geographic evidence for overcompensation. - Oecologia 118: 316-323.

Palmer, T. M., Young, T. P. and Stanton, M. L. 2000. Short-term dynamics of an acacia ant community. - Oecologia 123: 245-235. 
Pellew, R. A. P. 1983. The impact of elephant, giraffe and fire upon the Acacia tortilis woodlands of the Serengeti. - Afr. J. Ecol. 21: 41-78

Rosenthal, J. P. and Kotanen, P. M. 1994. Terrestrial plant tolerance to herbivory. - Trends Ecol. Evol. 9: 145-148.

Ruohomäki, K., Haukioja, E., Repka, S. and Lehtila, K. 1997. Leaf value: effects of damage to individual leaves on growth and reproduction of mountain birch shoots. Ecology 78: 2105-2117.

Sagers, C. L. and Coley, P. D. 1995. Benefits and costs of defense in a neotropical shrub. - Ecology 76: 1835-1843.

Sprugel, D. G., Hinckley, T. M. and Schaap, W. 1991. The theory and practice of branch autonomy. - Annu. Rev. Ecol. Syst. 22: 309-334.

Stanton, M. L., Palmer, T. M., Young, T. P. et al. 1999 Sterilization and canopy modification of a swollen thorn acacia tree by a plant-ant. - Nature 401: $578-581$.

Stock, W. D., Le Rouxm, D. and Van der Heyden, F. 1993. Regrowth and tannin production in woody and succulen karoo shrubs in response to simulated browsing. - Oecologia 96: $562-568$.

Strauss, S. Y. and Agrawal, A. A. 1999. The ecology and evolution of plant tolerance to herbivory. - Trends Ecol. Evol. 14: 179-185.

Tolvanen, A. and Laine, K. 1997. Effects of reproduction and artificial herbivory on vegetative growth and resource levels in deciduous and evergreen dwarf shrubs. - Can. J. Bot. 75: 656-666.

Vail, S. G. 1992. Selection for overcompensatory plant responses to herbivory: a mechanism for the evolution of plant-herbivore mutualism. - Am. Nat. 139: 1-8.

van der Meijden, E., Wijn, M. and Verkaar, H. J. 1988 Defense and regrowth, alternative plant strategies in the struggle against herbivores. - Oikos 51: 355-363.
Varnamkhasti, A. S., Milchunas, D. G., Lauenroth, W. K. and Goetz, H. 1995. Production and rain use efficiency in short-grass steppe: grazing history, defoliation and water resource. - J. Veg. Sci. 6: 787-796.

Whitham, T. G., Maschinshi, J., Larson, K. C. and Paige, K. N. 1991. Plant responses to herbivory: the continuum from negative to positive and underlying physiological mechanisms. - In: Price, P. W., Lewinsohn, T. M, Fernandes, G. W. and Benson, W. W. (eds), Plant-animal interactions: evolutionary ecology in tropical and temperate regions. John Wiley \& Sons, pp. $227-256$

Wrangham, R. W. and Waterman, P. G. 1981. Feeding behaviour of vervet monkeys on Acacia tortilis and Acacia xanthophloea: with special reference to reproductive strategies and tannin production. - J. Anim. Ecol. 50: $715-731$

Young, T. P. 1987. Increased thorn length in Acacia drepanolobium - an induced response to browsing. - Oecologia 71: 436-438.

Young, T. P. and Isbell, L. A. 1991. Sex differences in giraffe feeding ecology: energetic and social constraints. - Ethology 87: 79-89.

Young, T. P. and Okello, B. D. 1998. Relaxation of an induced defense after exclusion of herbivores: spines on Acacia drepanolobium. - Oecologia 115: 508-513.

Young, T. P., Stubblefield, C. H. and Isbell, L. A. 1997. Ants on swollen-thorn acacias: species coexistence in a simple system. - Oecologia 109: 98-107.

Young, T. P., Okello, B. D., Kinyua, D. and Palmer, T. M. 1998. KLEE: a long-term multi-species herbivore exclusion experiment in Laikipia, Kenya. - Afr. J. Range. Forage. Sci. 14: 94-102. 